\title{
The use of 3D printing model as tool for planning endoscopic treatment of benign airway stenosis
}

\author{
Giovanni Natale ${ }^{1}$, Alfonso Reginelli ${ }^{2}$, Domenico Testa ${ }^{3}$, Gaetano Motta ${ }^{3}$, Vincent Fang ${ }^{4}$, Mario Santini $^{1}$, \\ Alfonso Fiorelli ${ }^{1}$ \\ ${ }^{1}$ Division of Thoracic Surgery, ${ }^{2}$ Radiology Unit, ${ }^{3}$ Otolaryngology Unit, University of Campania "Luigi Vanvitelli”, Caserta, Italy; ${ }^{4}$ Department of \\ Thoracic Surgery, Shanghai Chest Hospital, Jiao Tong University, Shanghai 200030, China \\ Contributions: (I) Conception and design: A Fiorelli; (II) Administrative support: A Reginelli; (III) Provision of study materials or patients: D Testa; (IV) \\ Collection and assembly of data: G Natale, A Reginelli; (V) Data analysis and interpretation: M Santini, G Motta, V Fang; (VI) Manuscript writing: \\ All authors; (VII) Final approval of manuscript: All authors. \\ Correspondence to: Alfonso Fiorelli, MD, PhD. Thoracic Surgery Unit, Universitàdella Campania "Luigi Vanvitelli”, Piazza Miraglia, 2, I-80138 \\ Naples, Italy. Email: alfonso.fiorelli@unicampania.it.
}

\begin{abstract}
Benign tracheal stenosis is a life-threatening condition that needs a prompt treatment when the tracheal lumen is less than $5 \mathrm{~mm}$. In patients unfit for surgery, endoscopic dilation with stent insertion (if indicated) remains the main alternative to restore airway patency and assure ventilation. Endoscopic management of tracheal stenosis may be a cumbersome procedure, that sometimes takes a long time, and may be complicated by stent dislocation especially in cases of complex stenosis, near to vocal folds. In recent years, the $3 \mathrm{D}$ printing industry has undergone rapid development, and $3 \mathrm{D}$ printing model has been increasingly applied to different medical fields where therapeutic interventions rely on defining complex anatomic structural relationships. Thus, in this review we aimed to evaluate whether the use of $3 \mathrm{D}$ printing model as tool for preoperative planning could facilitate the endoscopic treatment of tracheal stenosis and improve outcome. Three papers evaluated this issue: one paper reported a consecutive series of patients while the remaining single case report. All authors concluded that the $3 \mathrm{D}$ model aided the understanding of patient's anatomy and the stenosis's characteristic. The possibility of recreating the endoscopic procedure in the $3 \mathrm{D}$ model facilitated and shorted the procedural time in live patient. Furthermore, the 3D model was additionally useful to choose the length, diameter and shape of stent and to define the exact distance of the proximal end of stent from the vocal folds after its insertion. Finally, it represented an educational tool for patients and his/her family to understand the procedure, and for residents and fellows to improve endoscopic skills.
\end{abstract}

Keywords: Benign tracheal stenosis; endoscopic treatment; 3D printing

Submitted Oct 17, 2019. Accepted for publication Jan 02, 2020.

doi: $10.21037 /$ tcr.2020.01.22

View this article at: http://dx.doi.org/10.21037/tcr.2020.01.22

\section{Introduction}

Benign tracheal stenosis is a life-threatening condition that needs a prompt treatment when the tracheal lumen is less than $5 \mathrm{~mm}$ (1). Surgery including resection and reconstruction of trachea is the treatment of choice while in patients unfit for surgery, endoscopic dilation with stent insertion (if indicated) remains the main alternative to restore airway patency and assure ventilation. However, endoscopic treatment may be challenging in case of subglottic (distant less than $2 \mathrm{~cm}$ from vocal folds) and complex (circumferential shape, $>1 \mathrm{~cm}$ in length, and with cartilage disruption) stenosis especially if requires the insertion of stent to maintain airway patency and prevent recurrence (2-5). Thus, the understanding patient's anatomy is crucial for the success of the procedure. Generally, high resolution chest computed tomography (HRCT) scan 


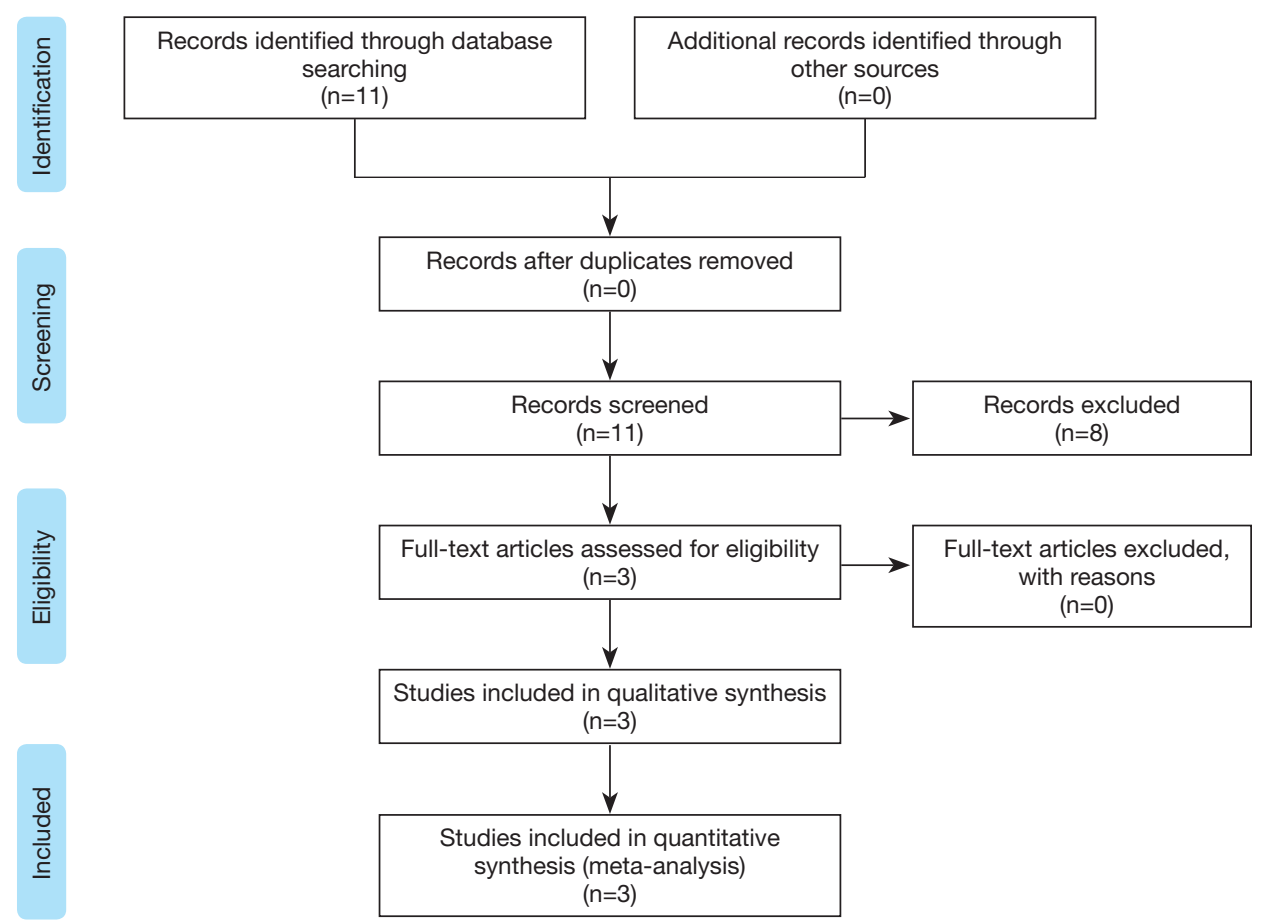

Figure 1 Flow chart based on PRISMA guideline (9).

images with 3D multi-planar reconstruction (MPR) have significantly improved the visualization of tracheal stenosis, but in some cases these models might be insufficient to define other aspects as the injury of cartilage and the distance between the stenosis and the vocal folds or to give information regarding the appropriate stent to implant. In recent years, the $3 \mathrm{D}$ printing industry has undergone rapid development (6), and 3D printing model has been increasingly applied to different medical fields where therapeutic interventions rely on defining complex anatomic structural relationships $(7,8)$.

Thus, the aim of this paper was to evaluate whether the use of $3 \mathrm{D}$ printing model as tool for preoperative planning could facilitate the endoscopic treatment of tracheal stenosis and improve outcome.

\section{Research strategy}

We performed a systematic review according to PRISMA guideline (9), searching all the articles related to the use of $3 \mathrm{D}$ printing for pre-operative planning treatments of benign tracheal stenoses published between January 1990 and August 2019 (Figure 1). Data about the demography, clinical presentation, pathology, diagnosis and treatment were collected. The search terms/syntax in PubMed was as follows: Benign Tracheal Stenosis OR "3D printing tracheal stenosis" OR "3D tracheal stenosis". Finally, a manual search was used to follow-up references from the retrieved study.

We included in the present analysis all clinical studies describing individual cases of $3 \mathrm{D}$ printing used as preoperative planning in management of benign tracheal stenosis. Abstracts; reviews; papers from the same groups; non-English language papers; and papers reporting the use of $3 \mathrm{D}$ model for different purposes (i.e., creating $3 \mathrm{D}$ printing airway stent, or planning surgical treatment of airway stenosis) were excluded.

\section{Results}

Eleven papers were identified on this topic. Eight papers were excluded as they reported the use of $3 \mathrm{D}$ printing technology to create an airway stent $(n=6)$ or to plan surgical treatment of airway stenosis $(n=2)$; thus 3 papers, summarized in Table 1, represented the object of the present review.

Guibert et al. (10) reported the use of pre-operative 3D printing tracheal model for the management of a complex, 


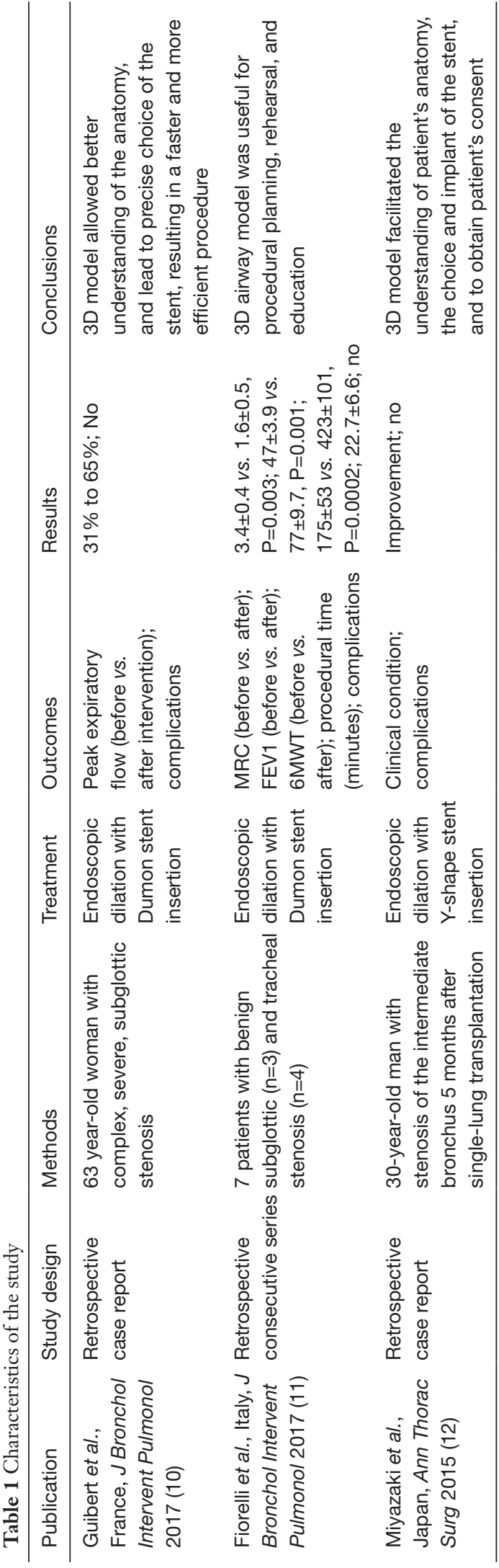

severe, subglottic stenosis in a 63 -year-old woman. The stenosis was distant less than $2 \mathrm{~cm}$ from vocal fold, had a diameter $<6 \mathrm{~mm}$, and infiltrated the esophagus. The $3 \mathrm{D}$ model was used to define the characteristics of the stenosis and to choose the airway stent. Patient underwent endoscopic dilation of the stenosis followed by silicone stent insertion. The procedure was successfully performed at the first attempt without complication. The patient's condition greatly improved after the procedure, the peak expiratory flow improved from $31 \%$ before the procedure to $65 \%$ after. $3 \mathrm{D}$ model allowed better understanding of the anatomy, and lead to precise choice of the stent, resulting in a faster and more efficient procedure.

Fiorelli et al. (11) reported the use of 3D printing model to plan endoscopic treatment in 7 consecutive patients with complex subglottic $(n=3)$ and tracheal stenosis $(n=4)$. The mean length and diameter of stenosis was $19 \pm 3.4$ and $5.8 \pm 1.2 \mathrm{~mm}$, respectively. In all cases, $3 \mathrm{D}$ printed model was used to define the anatomy of the stenosis and to plan endoscopic management. All patients underwent endoscopic dilation of the stenosis followed by silicone stent insertion. The mean operation time was $22.7 \pm 6.6$ minutes. No complications were observed during and after the procedure. A significant increase of Medical Research Council (MRC) dyspnoea scale $(3.4 \pm 0.4 v$ s. $1.6 \pm 0.5 ; \mathrm{P}=0.003)$; of forced expiratory volume in 1 second (FEV1\%) $(47 \pm 3.9 v s .77 \pm 9.7$; $\mathrm{P}=0.001)$ and of 6 -minute walking test $(6 \mathrm{MWT})(175 \pm 53 \mathrm{vs}$. $423 \pm 101 ; \mathrm{P}=0.0002)$ were obtained after the procedure (mean follow-up: $11.1 \pm 8.8$ months). $3 \mathrm{D}$ airway model was useful for procedural planning, rehearsal, and education.

Miyazaki et al. (12) reported the use of 3D printing model to plan endoscopic treatment in a 30-year-old man that developed stenosis of the intermediate bronchus five months after single-lung transplantation. 3D printed model was used to define the anatomy of the stenosis, to choose the stent and to plan its insertion. Patient underwent endoscopic dilation of the stenosis followed by insertion of modified Y-shape stent. No complications were seen during and after the procedure. Patient's clinical condition immediately improved after stent insertion and he was discharged 6 months after transplantation. 3D model facilitated the understanding of patient's anatomy, the chose and the implant of the stent, and the obtaining patient's signed consent for the procedure.

\section{Discussion}

The father of 3D printing is Charles "Chuck" Hull who 


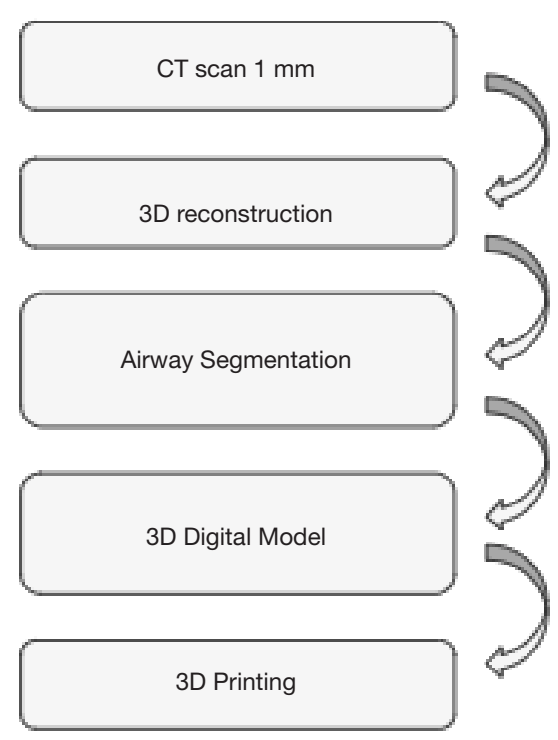

Figure 2 Flow chart for creating the 3D printing model.

created the first 3D printer (stereo lithography, SLA) in 1983 (13). His invention was based on the converting a digital file into a physical model using a 3D computeraided design (CAD) model. It built the 3D object layer by layer using the $2 \mathrm{D}$ slices by joining these layers together. Since 1990, 3D printing has been used in different fields of medicine (14). CT or MRI data were processed and manipulated by a dedicated software; this process generated a Standard Tessellation Language (STL) file. This file was read by a $3 \mathrm{D}$ printer that created a $3 \mathrm{D}$ anatomical model. Endoscopic management of tracheal stenosis may be a cumbersome procedure, that sometimes takes a long time, and may be complicated by stent dislocation especially in cases of complex stenosis, near to vocal folds. Thus, the $3 \mathrm{D}$ airway model used as tool for preoperative planning could facilitate endoscopic treatment and improve outcome.

The results of these analysis show that this strategy is still limited and performed only in very selected cases. We found three papers (10-12) that evaluated this issue; one paper reported a consecutive series of patients (11) while the remaining two $(10,12)$ single case report.

The strategy for creating the $3 \mathrm{D}$ printing model was similar in all reports (10-12) and summarized in Figure 2. Patient underwent High resolution CT scan with $1 \mathrm{~mm}$ cuts. A 3D reconstruction of airway was performed and the DICOM images were then uploaded in a dedicated software that developed the segmentation of the airway from the superior border of the epiglottis to $1-1.5 \mathrm{~cm}$ below the carina including the proximal bronchi. The 3D images were then saved as STL file that was read by a 3D printer to create the model (Figure 3). Despite different materials were used for the $3 \mathrm{D}$ printing model, in all cases (10-12) the model was rigid, fairly soft and flexible to reproduce all surgical or endoscopic manoeuvres for management of stenosis as in live patients. Only one study (11) reported the time and the cost for creating the $3 \mathrm{D}$ printing model. The average time was $6-7$ hours, resulting by the time spent for processing the images (average $2 \mathrm{~h}$ ) and by that for printing the 3D model. The average cost was 75-90 Euros and it was affected by the type of $3 \mathrm{D}$ material, the size of the model, the availability of the 3 printer in the hospital.

In all studies (10-12), the 3D model was used to planning the endoscopic treatment before carrying out it in live patient. All authors concluded that the 3D model aided the understanding of patient's anatomy and the stenosis's characteristic. The possibility of recreating the endoscopic procedure in the $3 \mathrm{D}$ model facilitated and shorted the procedural time in live patient. Yet, the $3 \mathrm{D}$ model was additionally useful to choose the length, diameter and shape of stent and to define the exact distance of the proximal end of stent from the vocal folds after its insertion. This point was crucial as the inappropriate choice of the stent could increase the risk of dislocation or of granulation due to constant mechanical irritation resulting from a stent digging into the airway tissue (15). Furthermore, 3D model represented an educational tool for patients and his/her family to understand the procedure, and for residents and fellows to improve endoscopic skills.

Obviously, our results should be considered with cautious. The small number of papers including only case reports and small case series, the retrospective nature of all studies, and the lack of a control group did not allow to draw definitive conclusions on the real advantage of using $3 \mathrm{D}$ model. Yet, the different characteristic and etiology of the stenosis as well as the strategy carried out to treat it, made difficult the comparison of the results among the studies.

Another important field of the $3 \mathrm{D}$ printing is the possibility of creating personalized airway stents that perfectly adapt to the patient's airway. In the last years, there are a growing number of case reports that reported the treatment of difficult airway stenosis with the implant of $3 \mathrm{D}$ printing stent. The ethical problems are the main limitations of these strategies as $3 \mathrm{D}$ materials suited for manufacturing endobronchial stents are still not approved 


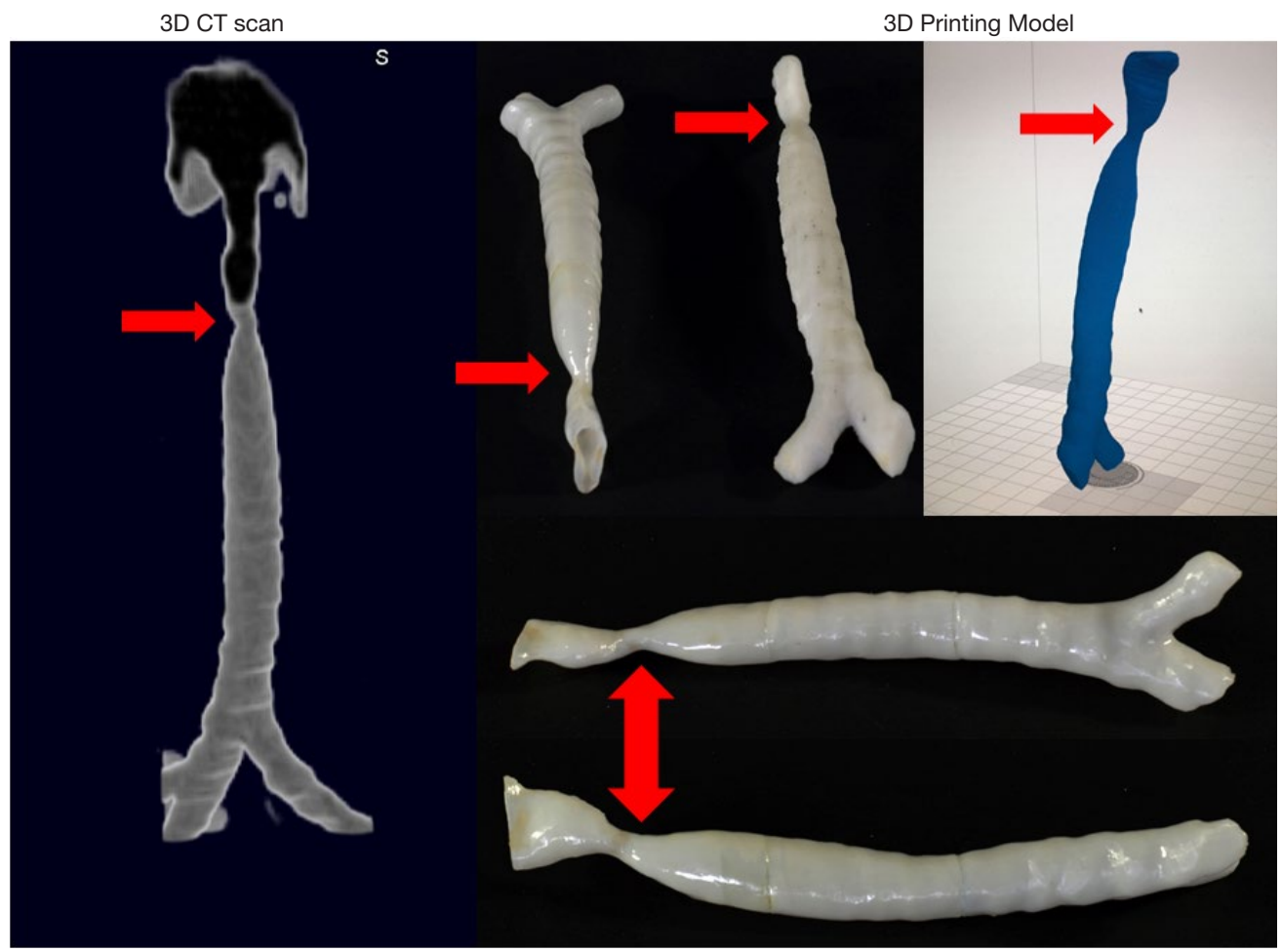

Figure 3 Example of 3D printing model of tracheal stenosis (red arrows).

by FDA. Thus, their use is allowed by Local Ethic Committee only as Humanitarian use device (HUD) for very selected cases.

\section{Conclusions}

The use of $3 \mathrm{D}$ printing model as tool for preoperative planning is a valuable strategy in the management of airway stenosis. This model allowed better understanding of the airway anatomy, and the extension of the stenosis, leading to precise choice of the stent, and resulted in a faster and more efficient procedure. Yet, it represented a valuable tool for trainees and fellows to improve their skills. The time and cost for model creation can be reduced by increasing physician's experience, and by acquisition of $3 \mathrm{D}$ printer from the hospital. Future application of this technology is $3 \mathrm{D}$ printing personalized airway prosthesis when $3 \mathrm{D}$ printable flexible and biocompatible material will be available.

\section{Acknowledgments}

Funding: None.

\section{Footnote}

Provenance and Peer Review: This article was commissioned by the Guest Editors (Benoit Jacques Bibas, Paulo Francisco Guerreiro Cardoso and Konrad Hoetzenecker) for the series "Recent Developments in Benign Tracheal Stenosis" published in Translational Cancer Research. The article has undergone external peer review.

Conflicts of Interest: All authors have completed the ICJME disclosure form (available at http://dx.doi.org/10.21037/ tcr.2020.01.22). The series "Recent Developments in Benign Tracheal Stenosis" was commissioned by the editorial office without any funding or sponsorship. The authors have no other conflicts of interest to declare.

Ethical Statement: The authors are accountable for all aspects of the work in ensuring that questions related to the accuracy or integrity of any part of the work are appropriately investigated and resolved.

Open Access Statement: This is an Open Access article distributed in accordance with the Creative Commons 
Attribution-NonCommercial-NoDerivs 4.0 International License (CC BY-NC-ND 4.0), which permits the noncommercial replication and distribution of the article with the strict proviso that no changes or edits are made and the original work is properly cited (including links to both the formal publication through the relevant DOI and the license). See: https://creativecommons.org/licenses/by-nc-nd/4.0/.

\section{References}

1. Grillo HC, Donahue DM, Mathisen DJ, et al. Post intubation tracheal stenosis. Treatment and results. J Thorac Cardiovasc Surg 1995;109:486-92.

2. Fiorelli A, Vicidomini G, Messina G, et al. Spontaneous expectoration of an obstructive fibrinous tracheal pseudomembrane after tracheal intubation. Eur J Cardiothorac Surg 2011;40:261-3.

3. Brichet A, Verkindre C, Dupont J, et al. Multidisciplinary approach to management of postintubation tracheal stenoses. Eur Respir J 1999;13:888-93.

4. Dalar L, Karasulu L, Abul Y, et al. Bronchoscopic treatment in the management of benign tracheal stenosis: choices for simple and complex tracheal stenosis. Ann Thorac Surg 2016;101:1310-7.

5. Fiorelli A, Caterino U, Raucci A, et al. A conical selfexpanding metallic stent for the management of critical complex tracheobronchial malignant stenosis. Interact Cardiovasc Thorac Surg 2017;24:293-5.

6. Gibson I, Rosen D, Stucker B. Additive Manufacturing Technologies 3D Printing, Rapid Prototyping, and Direct Digital Manufacturing. 2nd ed. New York: Springer, 2015.

Cite this article as: Natale G, Reginelli A, Testa D, Motta G, Fang V, Santini M, Fiorelli A. The use of 3D printing model as tool for planning endoscopic treatment of benign airway stenosis. Transl Cancer Res 2020;9(3):2117-2122. doi: $10.21037 /$ tcr.2020.01.22
7. Legocki AT, Duffy-Peter A, Scott AR. Benefits and Limitations of Entry-Level 3-Dimensional Printing of Maxillo facial Skeletal Models. JAMA Otolaryngol Head Neck Surg 2017;143:389-94.

8. Kaye R, Goldstein T, Zeltsman D, et al. Three dimensional printing: A review on the utility with in medicine and otolaryngology. Int J Pediatr Otorhinolaryngol 2016;89:145-8.

9. Liberati A, Altman DG, Tetzlaff J, et al. The PRISMA statement for reporting systematic reviews and metaanalyses of studies that evaluate health care interventions: explanation and elaboration. J Clin Epidemiol 2009;62:e1-34.

10. Guibert N, Moreno B, Hermant C. Usefulness of 3D Printing to Manage Compex Tracheal Stenosis. J Bronchology Interv Pulmonol 2017;24:e27-e29.

11. Fiorelli A, Scaramuzzi R, Minerva I, et al. Threedimensional (3D) Printed Model to Plan the Endoscopic Treatment of UpperAirway Stenosis. J Bronchology Interv Pulmonol 2018;25:349-54.

12. Miyazaki T, Yamasaki N, Tsuchiya T, et al. Airway stent insertion simulated with a three-dimensional printed airway model. Ann Thorac Surg 2015;99:e21-3.

13. Gross BC, Erkal JL, Lockwood SY, et al. Evaluation of 3D printing and its potential impact on biotechnology and the chimica sciences. Anal Chem. 2014;86:3240-53.

14. Aimar A, Palermo A, Innocenti B. The Role of 3D Printing in Medical Applications: A State of the Art. J Healthc Eng 2019;2019:5340616.

15. Fiorelli A, Mazzone S, Mazzone A, et al. The digital AcuBlade laser system to remove huge vocal fold granulations following subglottic air way stent. Interact Cardiovasc Thorac Surg 2013;17:591-3. 